Accepted version of the paper:

Romero-Muñoz, A., Fernández-Llamazares, Á., Moraes R., M., Larrea-Alcázar, D.M., Wordley, C.F.R. (2019) A pivotal year for Bolivian conservation policy. Nature Ecology \& Evolution 3: 866-869. doi: 10.1038/s41559-019-0893-3

Available at: https://www.nature.com/articles/s41559-019-0893-3

\title{
A pivotal year for Bolivian conservation policy
}

Alfredo Romero-Muñoz ${ }^{1 *}$, Álvaro Fernández-Llamazares ${ }^{2,3}$, Mónica Moraes R. ${ }^{4}$, Daniel M. Larrea-Alcázar ${ }^{4}$, Claire F.R. Wordley ${ }^{5}$

${ }^{1}$ Geography Department, Humboldt-University Berlin, Berlin, Germany

${ }^{2}$ Helsinki Institute of Sustainability Science (HELSUS), Faculty of Biological and Environmental Sciences, University of Helsinki FI-00014, Finland

${ }^{3}$ Global Change and Conservation (GCC), Organismal and Evolutionary Biology Research Programme, University of Helsinki, FI-00014, Finland

${ }^{4}$ Herbario Nacional de Bolivia, Instituto de Ecología, Universidad Mayor de San Andrés, c/27 Cota Cota campus universitario s/n, La Paz, Bolivia

${ }^{5}$ Department of Zoology, University of Cambridge, The David Attenborough Building, Pembroke St, Cambridge CB2 3QZ, UK

\section{Keywords}

Aichi Targets; Amazonia; Andes; Biodiversity, Mother Earth; Protected Areas; Rights of Nature; South America.

Correspondence: Alfredo Romero-Muñoz, Conservation Biogeography Group, Geography Department, Humboldt University Berlin, Berlin, Germany.

Email: alfredo.romero@geo.hu-berlin.de 


\section{As Bolivia approaches presidential elections in October 2019, the country's environmental leadership is at stake. We discuss urgent challenges and opportunities for reconciling conservation and societal needs in this megadiverse country.}

Bolivia, bridging Amazonia and the Andes, harbours astonishing biodiversity and ecosystems of outstanding global conservation concern. In the past decade Bolivia has been a pioneer on many environmental issues, legally encoding the Rights of Nature and proposing alternatives to market-based environmental policy instruments ${ }^{1}$. Bolivia's demands for strong and equitable action to reduce climate change have been decisive in shaping international environmental agreements such as the Paris Climate Agreement ${ }^{1}$. This leadership has been largely ushered in by President Evo Morales, widely viewed as a champion for nature and Indigenous rights. However, policies to further develop extraction and infrastructure in Bolivia's wilderness areas, including within its protected area network, are risking the country's position as a global environmental leader ${ }^{2}$.

After 13 years of conflicting policies (Fig. 1), the political discourse and presidential elections in October 2019 could set the environmental agenda for years to come. As debate heats up, we evaluate Bolivia's environmental policies since the Morales administration took office in 2006, particularly in relation to its Aichi Target 11 commitment to conserve at least $17 \%$ of its land by 2020 through a well-connected network of effective and equitable protected areas. We also provide suggestions to reconcile conservation and social goals in one of the most biodiverse countries on the planet.

\section{Bolivian conservation policy in perspective}

Bolivia is a megadiverse country and a global conservation priority, with some of the most extensive tropical forests in the world ${ }^{3,4}$. The country's 1.1 million square kilometres have remained relatively well conserved largely because of its low human population density and large, inaccessible areas. The current national protected area network encompasses around $15.8 \%$ of the country in 22 national protected areas. Environmental policies since Morales's rise to power in 2006 have advanced the recognition of the rights of Indigenous and rural peoples in environmental governance, and Indigenous peoples manage large and biodiverse areas of the country. The notion of 'Vivir Bien' ('living well'), enshrined in the Constitution in 2009, denotes a community-centric and ecologically balanced approach to development, while 
the revolutionary Bolivian Law of the Rights of Mother Earth, passed in 2010, places the intrinsic value of nature alongside that of humans ${ }^{5}$.

Despite these headline promises, the current administration has approved environmentally damaging activities that threaten Bolivia's protected area network and Indigenous territories (Fig. 1). These initiatives threaten decades of conservation efforts, the Indigenous peoples' millennia-long stewardship of nature, and Bolivia's credibility in international environmental policy forums.

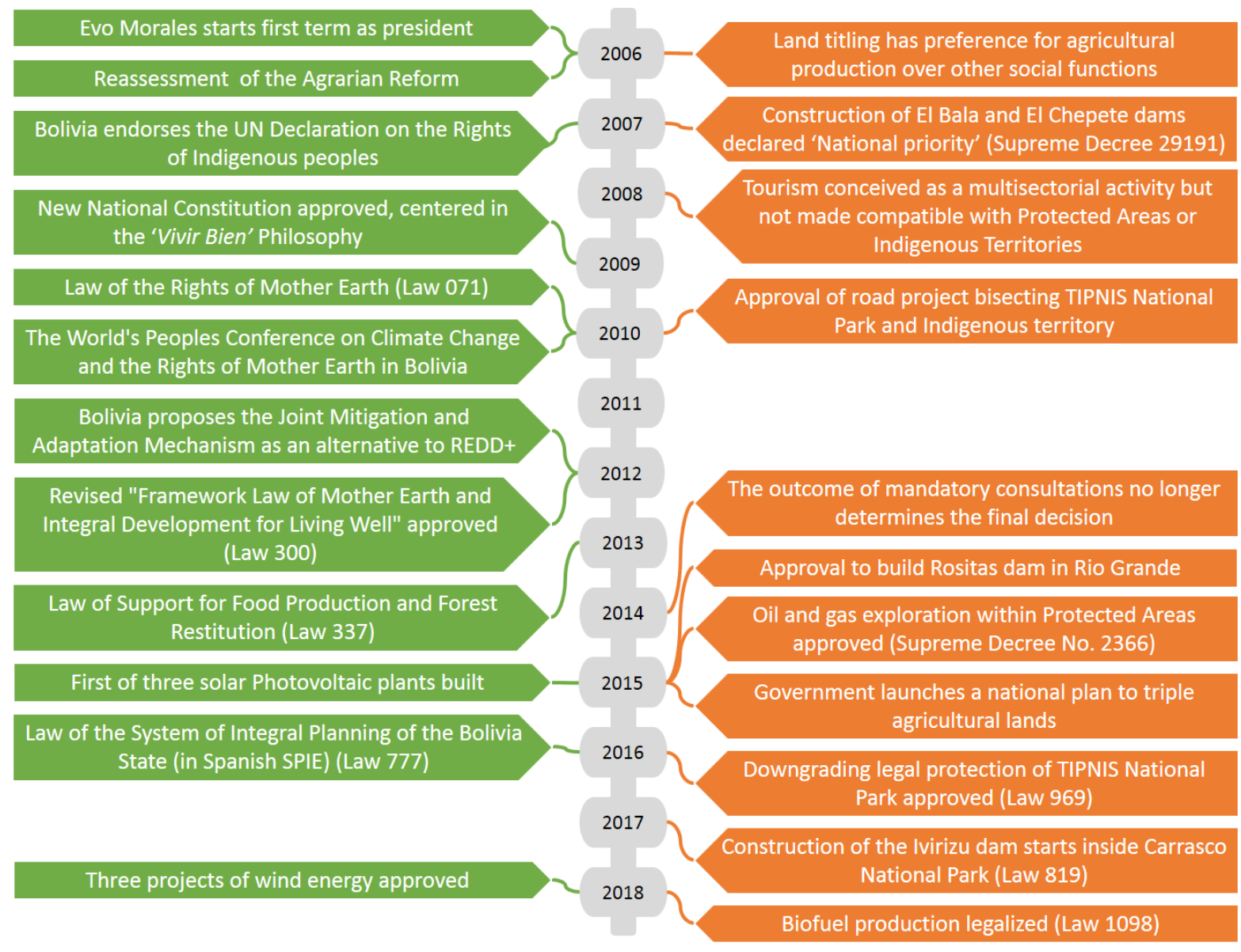

Figure 1. Policies that represent advances (left) and setbacks (right) for nature conservation in Bolivia since President Evo Morales's inception in 2006.

\section{Protected areas under pressure}

The majority of national protected areas in Bolivia are directly or indirectly threatened by the rapid expansion of commodity frontiers (Fig. 2). As a result, Bolivia has the second highest 
proportion of protected areas under intense human pressure in all of South America ${ }^{6}$, in spite of having one of the lowest human population densities.

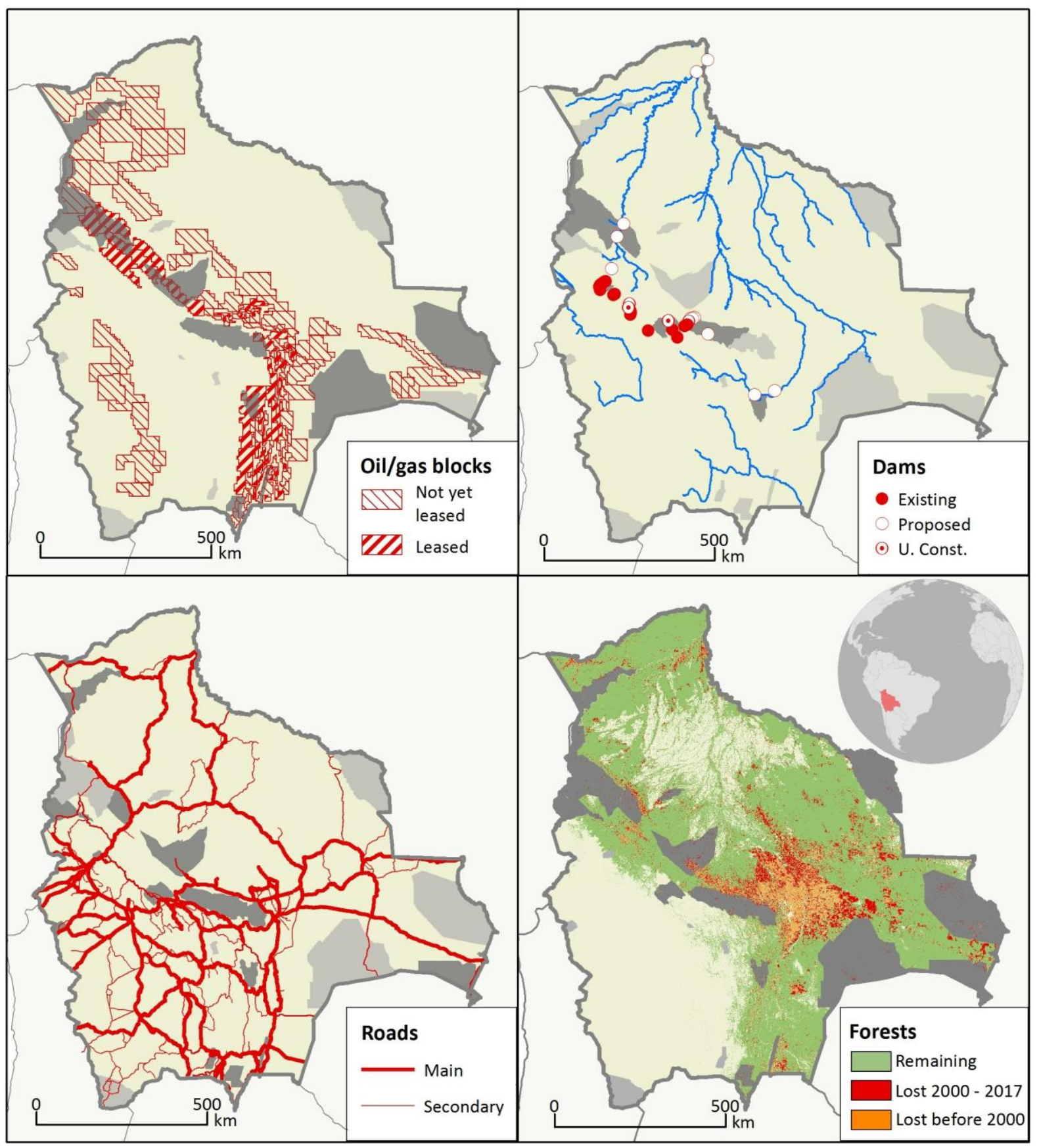

Figure 2. Bolivian National Protected areas (in grey) and their overlap with mega-dams, oil and gas blocks, main roads and deforestation. Darker grey national protected areas in each category are those that are less than $5 \mathrm{~km}$ from, or overlapped with, the mapped threat. All protected areas with forests suffered at least some deforestation inside their boundaries. (Sources: Protected areas: www.protectedplanet.net; Oil blocks, rivers, roads and forest extent and loss by 2000: http://geo.gob.bo; Dams: Ref 4; Forest change in 2000-2017: 

with ArcGIS 10.5.

In 2015, despite massive public outcry, the Government issued a decree enabling hydrocarbon exploration inside Bolivia's protected areas. Currently, 11 of the 22 national protected areas overlap with gas and oil blocks, which cover at least 17\% of Bolivia's protected surface (Fig. 2). Nearly half the expansion of the hydrocarbon frontier in Amazonia from 2008 to 2015 occurred in Bolivia ${ }^{7}$. This includes hydrocarbon exploration within Madidi National Park, which is thought to be the world's most biodiverse protected area ${ }^{8}$. Because of these trends, Bolivia is now one of the four countries whose biodiversity is at highest direct risk from fossil fuel development ${ }^{9}$. In addition, the country's tropical glaciers (which supply water to several main cities) and rainforests are highly vulnerable to the effects of global warming.

The country's freshwater and terrestrial biodiversity is further threatened by proliferating dams, primarily intended to export energy to neighbouring Brazil ${ }^{7,10}$. Bolivia currently has 21 dams, plus four under construction and 11 more proposed. Nine of these hydroelectric projects are located inside, or within five km of, protected areas (Fig. 2). Moreover, at least three dams are planned immediately upstream or downstream of seven Indigenous Territories ${ }^{7}$, causing displacement issues for Indigenous groups. Dams threaten river connectivity, disrupting the migration of fish critical to many Indigenous communities. They have already led to the disappearance of the emblematic dorado (Brachyplatystoma rousseauxii) from the Mamoré River ${ }^{7,10}$. In addition, gold mining has been expanding rapidly over the last five years in the Amazonian rivers of northern Bolivia, including inside protected areas. This emerging threat causes deforestation along rivers and water pollution.

Bolivia has prioritised road development to promote national integration and facilitate market access for rural producers. Unfortunately, unprecedented road expansion is opening extensive areas of high biodiversity value to agricultural encroachment, deforestation, and overexploitation ${ }^{11}$. At least nine protected areas in the Bolivian Amazon are already fragmented by roads (Fig. 2). The most infamous case is the controversial road set to cut across the heart of the highly biodiverse Isiboro Secure Indigenous Territory and National Park (TIPNIS) ${ }^{11}$. Alarming levels of deforestation have already occurred along built sections of the road within the park, triggering one of the highest-profile social-ecological conflicts in South American history ${ }^{11}$. 
Despite Bolivia's constitution protecting the right of Indigenous peoples to give or withhold their Free, Prior and Informed Consent in relation to infrastructure development and resource extraction in their territories ${ }^{5}$, a 2015 Supreme Decree (No. 2298) allows the Government to decide the consultation procedure and timing with national Indigenous organisations rather than with the locally affected communities. Thus, Indigenous communities increasingly find themselves on the frontlines of conflict and even violence if they contest development projects.

\section{Threats to connectivity of protected areas from agricultural expansion}

As well as threats to the integrity of protected areas, agricultural expansion is causing massive biodiversity loss and eroding protected area connectivity. In 2014, the Bolivian government announced plans to expand the country's agricultural surface from 3.5 to 13 million hectares in the next decade, tripling crop and meat outputs ${ }^{12}$. Bolivia already has the fifth greatest loss of primary forest area globally from 1990 to 2015, mainly due to large-scale commercial cattle ranching and cropland expansion ${ }^{4}$ (Fig. 2). The deforestation hotspots in South America are shifting from Brazil towards Bolivia, with the country's Santa Cruz department becoming the number one deforestation hotspot across the entire Amazon Basin ${ }^{13}$.

Beef and soybean production to fuel growing national and international demands are the country's foremost drivers of deforestation, followed by coca cultivation, which expands deep inside protected areas ${ }^{11,12}$ (Fig. 2). Furthermore, Bolivia now allows biofuel production, which will extend sugar-cane plantations to 350,000 ha (Law 1098). Agriculture is expanding at the expense of sustainable forestry, in which Bolivia was the global leader from the 1990s to early 2000s; these forests are now deemed 'forests without use' by the Government. If these trends continue, Bolivia could lose more than half of its remaining forests by $2050^{12}$. Reduced connectivity between protected areas jeopardizes the country's ability to deliver its international commitment to an effective and well-connected protected area network, even if the area-based protection targets are met.

\section{Policies for Bolivia's future}

Bolivia can achieve good living standards for its citizens without jeopardising its natural heritage. The IUCN has urgently called on Parties to the Convention on Biological Diversity to adopt "no-go" principles for protected areas, legally prohibiting extractive, agricultural and 
infrastructure development inside them. Bolivia's Law of the Rights of Mother Earth provides a solid legal framework for Bolivia to pioneer and enforce this "no go" provision ${ }^{5}$.

Bolivia could rigorously implement large-scale, proactive, participatory, and strategic land-use planning. Powerful multi-criteria optimization tools are now available to guide land-use planning, by spatially prioritizing land-uses outside protected areas to maximize human benefits, while limiting biodiversity loss and maintaining connectivity between protected areas; but they have yet to be used in the country ${ }^{14,15}$. In addition, the current implementation of environmental impact assessments for development projects in Bolivia is deficient and should be improved, as should mitigation, restoration, and other environmental management measures ${ }^{16}$. Energy policy must rapidly move beyond fossil fuels, biofuels, and mega-dams, and focus more on solar, wind, and geothermal power. Bolivia has one of the highest levels of solar radiation on the planet, mostly in the Altiplano region, where solar panel installation could theoretically produce enough energy to supply the entire world ${ }^{17}$.

As Bolivia approaches presidential elections, the question of how to make the philosophy of Vivir Bien a reality should be a key part of political debate, and be explicitly described in candidates' manifestos. Among eight authorised presidential candidates, several recent polls suggest two clear front-runners, Carlos Mesa and president Evo Morales. Mesa has stated that the environment would be one of the four pillars of his government if elected. His unpublished introductory manifesto (presented to Bolivia's Electoral Tribunal and provided by his team on 25-03-2019 upon request from us) emphasizes a diversified local economy that is socially and environmentally responsible, and which moves away from extractivism. It states that a notion of 'common good' must include non-human life; that energy generation must rapidly shift towards renewables; that mining will continue, but damage must be minimised; and that increasing agricultural productivity should be prioritised rather than 'irresponsibly' expanding the agricultural frontier. The Morales administration plan for 2020-2025 is publicly available. It focuses on economic growth, agricultural expansion, and financing development through the 'nationalisation, industrialisation and commercialisation of natural resources in harmony and balance with Mother Earth'. It states the importance of sustainable use of nature without resorting to market-based mechanisms, and mentions that the protected area network will be consolidated. While economic growth and wealth distribution are important issues for the elections in Bolivia, we believe that nature, climate change, and Indigenous rights are also key topics of electoral debate for Bolivians who are rightly proud of their unique natural heritage. 
Bolivia has the highest percentage of Indigenous population in Latin America (>40\%), and a relatively high proportion of these people retain traditional livelihoods and worldviews emphasising the responsibility of humans towards Mother Earth. Many Indigenous groups are strongly committed to protecting the natural environment, and a broader swathe of the Bolivian public is growing aware of environmental issues. Bolivians should be presented with detailed manifestos addressing environmental and other concerns from presidential candidates, and be able to follow debates on how each candidate proposes to address Indigenous and environmental issues, before the October election. Further, they should be confident that environmental rhetoric will be translated into action. We hope that the post-2019 Bolivian administration will honour its international commitment towards Mother Earth, and return the country to the vanguard of the environmental movement of the Global South.

\section{Acknowledgements}

We thank T. Kuemmerle, J. Geldman, A. Ghodoussi for helpful discussions and comments to previous versions of the manuscript as well as A. Balmford, V. Reyes-García, and R. Rocha for enlightening discussions about conservation policies. A. Gyawali provided cartographic assistance. Alfredo Romero-Muñoz acknowledges financial support from the German Research Foundation (Grant Number: KU 2458/5-1) and the German Ministry of Education and Research (Grant Number: 031B0034A), and Fernández-Llamazares acknowledges financial support from the Academy of Finland (Grant Agreement No. 311176).

\section{References}

1 Borie, M. \& Hulme, M. Environmental Science and Policy 54, 487-496, (2015).

2 Hope, J. Extractive Industries and Society 3, 922-929, (2016).

3 Ibisch, P. L. \& Mérida, G. (eds). Biodiversidad: La riqueza de Bolivia. (Editorial FAN, 2003).

4 Morales-Hidalgo, D., Oswalt, S. N. \& Somanathan, E. Forest Ecology and Management 352, 68-77, (2015).

5 Lalander, R. The International Journal of Human Rights 21, 464-481, (2016).

$6 \quad$ Jones, K. R. et al. Science 360, 788-791, (2018).

$7 \quad$ Finer, M. et al. Environmental Research Letters 10, (2015).

8 Identidad Madidi \& SERNAP. Informe Científico 2015. Relevamientos de biodiversidad en el Parque Nacional y Área Natural de Manejo Integrado Madidi. 1180 (Wildlife Conservation Society and Servicio Nacional de Áreas Protegidas, Bolivia, 2016).

9 Butt, N. et al. Science 342, 425-426, (2013).

10 Anderson, E. P. et al. Science Advances 4, eaao1642, (2018).

11 Fernández-Llamazares, Á. et al. Current Biology 28, R15-R16, (2018). 
12 Tejada, G. et al. Environmental research 144, 49-63, (2016).

13 Kalamandeen, M. et al. Scientific Reports 8, 1-10, (2018).

14 Lambin, E. F. \& Meyfroidt, P. Proceedings of the National Academy of Sciences 108, 3465-3472, (2011).

15 Laurance, W. F., Sayer, J. \& Cassman, K. G. Trends in ecology \& evolution 29, 107116, (2014).

16 Rodríguez Osuna, V., Navarro Sánchez, G., Sommer, J. H. \& Biber-Freudenberger, L. (eds). Towards the integration of biodiversity in Environmental Impact Assessments of Bolivia. (Center for Development Research (ZEF)-University of Bonn and Universidad Católica Boliviana, 2017).

17 Kabir, E., et al. Renewable and Sustainable Energy Reviews 82, 894-900, (2018). 